\title{
INTELIGENCIAS Y CREATIVIDAD: TEORÍA, METÁFORA, VIVENCIA
}

\author{
Maurizia D'Antoni \\ Humberto Malavassi
}

\section{Una introducción al "cerebro inteligente"}

Antes de empezar a presentar el tema de la creatividad desde el punto de vista de la vivencia personal, es importante introducir brevemente el tema del desarrollo genético y de la formación y localización de las diferentes funciones en el cerebro.

En efecto, conocer la manera en que evolucionó el "cerebro emocional", es decir la parte del cerebro que es sede de las respuestas emocionales en los seres humanos, nos permite comprender mejor esas funciones; lo interesante sin duda es que esa parte de nuestro cerebro nace con una función olfativa (Le Doux, 1996). Los seres primitivos que desarrollaron esa función pudieron reaccionar ante los 
impulsos primarios, el hambre o el sexo por ejemplo, y discriminar lo que era nocivo (como las plantas venenosas) de lo que había disponible de manera inofensiva. Lo hicieron discriminando a través de sus narices, pero la parte del cerebro que procesaba la información proveniente del olfato es la misma parte que permite responder "emocionalmente".

El lóbulo olfativo del cerebro asegura la posibilidad de reaccionar activamente: morder, escupir, acercarse, huir, perseguir. La zona del cerebro que procesa, a través del olor, la posibilidad del peligro también es la que permite una respuesta inmediata de tipo activo. Después, es el sistema límbico el que interpone la posibilidad del aprendizaje y la memoria: nuestros antepasados aprendieron lo que era peligroso y archivaron en sus mentes la nueva información. Reflexionamos así lo que los educadores sabemos por la experiencia: el aprendizaje se basa también, y por buena parte, en la memoria.

Luego, el rinencéfalo se conecta con las primeras capas del "cerebro pensante": se llama la neocorteza. Los reptiles, que no tienen ese cerebro, han demostrado en la investigación carecer esencialmente de una de las capacidades constituyentes del ser humano: el sentido de protección de la progenie. Los pequeños homo sapiens pueden así nacer inmaduros en varios sentidos y terminar el proceso de maduración a la par de los primeros aprendizajes, en el seno de la comunidad humana.

La neocorteza presenta una evolución hacia los animales superiores: es allí donde localizamos la capacidad de ser autorreflexivos y de tener sentimientos hacia uno mismo.

A su vez, es el sistema límbico que, por ejemplo, "ordena" producir el llanto; es el depósito de la memoria emocional. Uno de sus componentes, la amígdala, si es separada quirúrgicamente del resto del sistema produce en las personas así lesionadas una "ceguera afectiva" (Goleman, 1996). 
La amígdala es considerada por Le Doux un sistema anticuado que reacciona cuando se presenta un evento importante antes de tener toda la información: es fundamental para mantenernos con vida, aunque en ocasiones, el sistema construido para reacciones rápidas a favor de nuestra sobrevivencia produzca más bien la muerte, como recuerda Daniel Goleman a propósito de un padre que le disparó a su hija, en circunstancias tales que crearon en él un estado de alerta en contra de un supuesto ladrón.

Las emociones son los hilos que tienen unida nuestra vida mental: de no poder colocar nuestras capacidades y nuestras acciones en un contexto afectivo seríamos idiotas que saben, personas discapacitadas, incapaces de situarse eficaz y serenamente en el mundo.

En la serie televisiva "Star Trek" se presenta un personaje que, en la versión más antigua del programa se llama Spock y viene del planeta Vulcano, y en la versión más reciente se llama Data ("datos" en inglés), y es un androide, una máquina. La característica de los dos personajes es ser absolutamente racionales, capaces de tomar decisiones fríamente, sin hacerse "condicionar" por los sentimientos y las emociones. Evidentemente, el cariño que los espectadores todavía le tributan a la serie y a los personajes en cuestión, después de años de la salida al aire de los programas citados, muestra que el concepto de una racionalidad "pura", sin contaminación emocional nos atrae y tiene un poderoso encanto para los que vivimos en esta época. Sin embargo, según lo que conocemos del cerebro humano, los personajes citados serían una contradicción en términos, ya que la parte emocional de los seres que conocemos tienen la tarea de vincular funciones mentales entre sí, hacerlas inteligibles y disponibles. A la vez, nuestro cerebro lleva las marcas de una mente antigua que aprendió a ser inteligente leyendo e interpretando olores 
u otros estímulos proveniente del ambiente, y le atribuyó al miedo y a la memoria funciones complementarias, para poder reaccionar rápidamente. Somos la especie que gracias a esas respuestas sobrevivió; y de esa especie llevamos el rastro en nuestro ADN.

Si trasladamos nuestra reflexión el alumno racional que forma parte de nuestro imaginario docente es, por lo tanto, una falacia: las emociones no son trabas para la inteligencia sino un tejido conectivo necesario que tenemos que saber reconocer, apreciar y cultivar en las aulas. Tenemos que hacerlo sin que eso nos signifique una carga más en la clase tradicional que nos preparamos a dar y que interrumpimos cuando la moda o la imposición dictan para incluirlo: entonces se imparte cátedra diez minutos acerca de "valores"; y el año entrante será historia olvidada.

Entre emociones y aparato cognitivo se sitúa también la creatividad; característica de las personas olvidadas por nuestra escuela y a la vez absolutamente necesaria para salvar el mundo en el que vivimos.

\section{Una metáfora acerca de creatividad}

Para ejemplificar la vinculación entre "creatividad" e "inteligencias personales" es útil proponer la metáfora de la orquesta ${ }^{1}$.

En los seres humanos así como en los animales, el desarrollo se lleva a cabo de manera natural. Se trata, en el caso expuesto, de las funciones de forma elemental o primaria. En los seres humanos el desarrollo cultural transforma las funciones primarias en funciones psíquicas superiores.

\footnotetext{
1 Entendemos por metáfora una figura retórica que consiste en trasladar a un objeto el término propio de otro, según una relación analógica. El estudio de la metáfora es capaz de elucidar el funcionamiento mismo de la mente humana ya que su creación recalca uno de los mecanismos de funcionamiento de nuestro inconsciente.
} 
Una orquesta sinfónica es una entidad compuesta por un número de músicos que puede rondar los cien elementos y que produce un solo sonido. No todos los músicos tocan siempre, ni tocan lo mismo. Hay sonidos y silencios que les dejan construir diferentes texturas, según lo que tocan, y la intensidad con que tocan. Ellos construyen diferentes timbres sonoros: el director se encarga, por medio de sus conocimientos, sus estudios y su intuición de hacer que el todo se convierta en una interpretación grupal.

Los esfuerzos y las capacidades de los diferentes profesionales convergen en un único resultado: el concierto. El fracaso de uno es el fracaso de todos. El buen desempeño de un individuo también se refleja en lo colectivo, empezando por la afinación, que es la adecuación de todos los instrumentos a una misma altura de sonido. La orquesta expresa también un ritmo y una interpretación: en ambos ejemplos, la excelencia personal implica capacidad de acople con el grupo en pro de un resultado colectivo.

La inteligencia musical, la kinestésica, la lógica, o cualquier otra inteligencia que sea necesaria en el proceso de ejecución de una obra musical por parte de una orquesta sinfónica, tiene que acoplarse satisfactoriamente a la creatividad de la persona y con su inteligencia inter e intra personal.

En efecto, la inteligencia intrapersonal es una de las herramientas que posibilita que el sonido de cien personas se convierta en uno solo. El aporte creativo, necesario en la interpretación artística se vincula con la disciplina y la toma de decisión del músico con sus compañeros y con el director.

Aquí está claro que la creatividad personal deja de ser eficaz si se sale del contexto, si se transforma en nota desafinada, en interpretación divergente con respecto a la decisión del grupo, en una gestualidad bizarra: al contrario, creatividad significa "pensamiento divergente", pero no en 
un contexto social que pueda aprovechar el recurso indicado. Llevar a la práctica educativa los conocimientos que tenemos acerca de inteligencias múltiples y de inteligencias personales de un lado y de creatividad del otro, representa en este momento histórico una emergencia: los datos acerca de la educación secundaria consignados por el informe del Estado de la Nación así lo prueban.

\section{3. ¿Por qué la creatividad?}

Deseamos rescatar este rasgo personal en primera instancia porque la creatividad empuja al individuo a tomar decisiones ya que está vinculada con el sentido crítico. Consideramos que ambas características son claves en el ámbito de nuestra práctica educativa. Creatividad implica de alguna manera "estar en contra", oponerse, con la capacidad de conocer por qué, y potencialmente ofrecer o ir en busca de soluciones alternativas.

Las funciones superiores, que se puede llamar también sociales, tienen la característica de trascender la determinación ambiental, y se generan de manera consciente a partir del dominio ejercido por el ser humano y su intención. De la misma manera, tienen origen social y a la vez están culturalmente mediadas por sistemas de signos.

Memoria e imaginación son dos de las funciones psíquicas superiores que se originan por dominio consciente y voluntario en nuestra especie. Vigotsky llama imaginación a algo que se manifiesta en toda la especie, se activa de manera autónoma, distanciándose de la cognición inmediata, pero aun así no carece de sentido práctico. Es la imaginación la que permite la vida cultural y posibilita la creación artística.

Es interesante iniciar desde la concepción vigotskiana de imaginación, el concepto de creatividad, recordando que 
Vigotsky se interesa en la relación que existe entre emoción e intelecto, a la vez que aboga por la superación de una visión de la imaginación como acción psíquicamente individual.

Nuestra intención tiene sus bases en esa concepción de creatividad/imaginación y en esa búsqueda de vínculos entre actividades tradicionalmente entendidas como propias de la esfera cognitiva y las actividades de la imaginación. Por lo tanto, se presentará a continuación el relato de algunas vivencias, con la intención de concretar la búsqueda indicada. Las actividades que se exponen han sido llevadas a cabo por uno de los docentes autores de este documento.

\section{Las vivencias del aula}

Apoyados en las Teorías de las Inteligencias Múltiples y de la creatividad el docente puede realizar en su vivencia cotidiana en el aula actividades que no requieren grandes recursos materiales, ni tiempo excesivo de su parte.

Una de las actividades realizadas para vincular la creatividad y la interdisciplinariedad tuvo como tema central el bolero. Se trata de un lenguaje típicamente latinoamericano que contienen tres mensajes: la letra, la canción y el mensaje corporal.

El taller se realizó en el Conservatorio Castella, institución única en Costa Rica, los estudiantes de Escuela Primaria y de Colegio reciben clases de las materias académicas tradicionales en las mañanas y clases de artes en las tardes.

Se preparó la actividad, por lo tanto, involucrando a la profesora de español y al profesor de música: el bolero se vio a partir de su historia y su origen; se analizaron las letras como se haría con cualquier obra literaria poética. Lo mismo 
se hizo con la música, que fue arreglada para ser tocada con guitarra y saxofón.

Se quería proponer el tema del bolero no como un tema de una clase corriente, sino en calidad de acontecimiento que involucraba los conocimientos previos y utilizaba la vivencia personal para el aprendizaje, inspirados por la experiencia constructivista. Se escogió la canción "Cómo fue", que forma parte del panorama cultural de muchos latinoamericanos.

La clase permitió expresarse y participar bailando y cantando pero a la vez pudo teorizar y explicar lo que se había aprendido y recopilado sobre el tema. Uno de los objetivos fue que los alumnos se acercaran al significado de los aspectos de la identidad y la cultura, a través de una forma musical típicamente latinoamericana. La experiencia resultó extremadamente positiva y se desarrolló en medio de un ambiente participativo, activo y bullicioso, sin convertirse en desordenado. Los profesores que se involucraron en la actividad, así como los alumnos manifestaron una sensación de bienestar, que lastimosamente no siempre acompaña las actividades que se desarrollan en los colegios.

Los participantes expresaron haber incorporado nuevas enseñanzas: cada cosa tiene un por qué, también la tienen las formas musicales, las maneras de bailar que se dan por sentadas, por ser parte de un repertorio cultural conocido. Se apreció cómo la música y la danza tienen un origen y una razón de ser.

La sensualidad que la danza expresa fue utilizada también como una herramienta útil para enseñar: se convivió con la música y se aprovechó el sentimiento de amor que las letras expresan para vincular la actividad con la vivencia de los muchachos y las emociones, bien conocidas por los adolescentes. 
Se vio cómo el romanticismo latinoamericano se acopla con la vivencia personal, se entiende en su expresión literaria, se expresa a través de la música: luego los alumnos lo cantaron y lo bailaron, para apropiarse de su sentido cultural.

Una actividad como la que se ejemplificó anteriormente permite a los estudiantes expresar sus recursos creativos en un ambiente que no es amenazante, el aprendizaje no significa para quienes participan en la experiencia, arriesgar su autoestima y enfrentarse al error de manera traumática.

Hemos visto cómo las aulas de colegio reflejan aspectos de la cultura costarricense: la chota, las envidias, las maneras destructivas de socializar, culturalmente determinadas, son conductas que se aprenden y reproducen y en las aulas afecta la confianza de los estudiantes. Evidentemente, en el aprendizaje el error es parte del proceso, y es una parte muy importante: se podría decir que, en nuestra concepción de aprendizaje, el error es aprendizaje ya que permite ensayar conductas y activar la memoria, recorrer el camino que lleva a la incorporación de lo nuevo, una y otra vez.

En nuestras escuelas sentimos que hay materias y momentos, etapas en las que el error es más admitido que en otras. Lastimosamente, muchas veces equivocarse se transforma en un momento conflictivo, humillante para el alumno y frustrante para el docente.

Un taller de música que un grupo de estudiantes desarrolló en Costa Rica, con el famoso saxofonista y pedagogo de la música Frederick Hemke, puede servir para ejemplificar la utilidad del error en el campo de la enseñanza musical. Los estudiantes que estaban aprendiendo a tocar el instrumento se presentaron ante el artista extranjero y se dieron cuenta que el docente corregía algo diferente a cada 
uno de ellos: para algunos hubo sugerencias acerca de la postura, otros de la respiración, otros de la digitación. Fue evidente que el error es la fuente donde la enseñanza inicia: el profesor señalaba, por ejemplo, la postura correcta, no estigmatizaba al alumno: le impulsaba a mejorar y obtener mejores resultados en su desempeño.

Todo lo anterior se observó en la clase de un profesor que declara no considerarse a sí mismo un producto acabado, a pesar de la fama mundial que ha alcanzado.

Se observa, en el transcurso de nuestra actividad profesional, casos de profesores que se burlan de los alumnos, inclusive a escala universitaria. Como resultado tenemos a estudiantes que no quieren exhibirse, no quieren mostrar sus trabajos en público y, además, a docentes que no publican por el miedo de recibir críticas. Ni hablar entonces de atreverse a ser creativo: si el escollo que los alumnos enfrentan es reproducir de manera perfecta, sin incurrir en el error lo que se le está enseñando, no existirá la posibilidad de estimularlos a que inventen, que se figuren ideas, métodos, abordajes novedosos y divergentes.

El miedo a ser evaluados está presente en los alumnos de las primeras clases de la escuela primaria también: probablemente los niños aprenden de sus hermanos mayores o de sus familiares y amigos que ser evaluados es un momento crítico: hemos comprobado a través de la experiencia como también los alumnos de primer grado demuestran cierta ansiedad cuando se menciona una prueba.

A raíz de la observación que se acaba de mencionar, se realizó una actividad en las clases de la escuela primaria de una institución privada, el Colegio Yorkín. Se les propuso a los pequeños estudiantes desarrollar un tema y luego evaluarlos de manera diferente. El tema fue el de los paisajes sonoros: se convenció a los alumnos que ellos conocían del argumento y que serían evaluados sobre lo que conocían 
muy bien, no sobre materia nueva o temas acabados de ver. Se les pidió realizar una reproducción de ambientes sonoros que conocían: el comedor, el recreo, la salida de clase... Para hacerlo, ellos disponían de muy pocos minutos, no podían utilizar instrumentos musicales, sino que se esperaba de ellos que construyeran sus "entornos sonoros". Lo hacían reproduciendo los sonidos con sus cuerpos o con elementos presentes en el aula. Eso sí, sin utilizar palabras.

Los niños vieron que lo podían hacer y que sus compañeros identificaban con mucha facilidad el ambiente sonoro representado. Eso significaba que la reconstrucción había sido exitosa. La actividad tenía la finalidad de disminuir el miedo a la evaluación, probándole a los alumnos que ellos eran portadores de conocimiento, sin saberlo. A la vez, se iniciaba la sensibilización acerca del ambiente sonoro, sobre la que se puede construir una sensibilidad musical más y más desarrollada.

La actividad se prestaba para vincularse con otros temas como son la contaminación sonora, el respeto a los demás y las agresiones acústicas.

Finalmente, se trataba de una actividad grupal en la que los límites de tiempo, en el uso de los medios para reproducir sonidos, provocaban y casi obligaban el uso de la creatividad por parte de los estudiantes.

También, la actividad tenía como propósito enseñar a escuchar, la base de la sensibilidad en el ámbito musical así como el respeto hacia los demás: se aprende de esta manera a respetar los turnos en un debate así como a tomar en cuenta las ideas ajenas en una discusión. Los estudiantes aprenden a preguntarse cuánto escuchan antes de proponer su punto de vista. La capacidad de escucha es primero reproducida por imitación del adulto, la emulación es un primer momento. Luego, la escucha se transforma en la herramienta necesaria para poder argumentar en un contexto 
de respeto y reconocimiento del otro que supone a la vez la autoasertividad. Estas son las bases que los estudiantes necesitan para construir la confianza en sí mismos.

Creemos que pueden existir intervenciones de los adultos durante la enseñanza capaces de mediar entre los alumnos y su entorno, las mismas sirven de directrices ordenadoras en un ambiente conocido pero no siempre descubierto. A la vez, esas intervenciones pueden servir para poner las bases de la autoasertividad y de la creatividad que, en relación con la imaginación creativa y al pensamiento divergente son parte de las funciones psíquicas que estamos denominando inteligencias personales.

\section{BIBLIOGRAFÍA}

Castorina, J. A., Ferreiro, E., Kohl de Oliveira, M. y Lerner, D. PiagetVigotsky: contribuciones para replantear el debate. Paidós Educador, Buenos Aires - Barcelona-México.

Brockert. S. y Braun. G. 1996. Los test de la inteligencia emocional. Trad. Esp. Robin Book. Barcelona.

Goleman, D. 1996. Inteligencia emocional. Trad. Esp. Kairós, Barcelona.

Le Doux, J., 1996. El cerebro emocional. Trad. Esp. Editorial Planeta.

Moll C., L. (compilador). 1993. Vigotsky y la Educación. Aique, Buenos Aires.

Murray-Schafer, R. 1977. The tuning of the world. McClelland and Stewart Limited, Toronto.

Roche, R. y Neus, S. 1998. Educación prosocial de las emociones, valores y actitudes positivas. Trad. Esp. Blume, Barcelona. 
Schiefelbein, E., 1994. "Estrategias para elevar la calidad de la educación". En: La educación. Revista Interamericana de Desarrollo Educativo. Año XXXVIII NNo 17, I. Pp. 1-18. 